Avaliable online at

https://www.syekhnurjati.ac.id/jurnal/index.php/tamaddun/index

Published by Departement of History and Islamic Culture, Faculty of

Ushuluddin Adab and Dakwah IAIN Syekh Nurjati Cirebon, Indonesia

\title{
Sejarah Mata Uang Masa Kepemimpinan Muawiyah bin Abu Sufyan
}

\author{
Camelia Rizka Maulida Syukur \\ Program Magister Ilmu Agama Islam \\ Universitas Islam Indonesia
}

cameliamaulida13@gmail.com

\begin{abstract}
:
During the Umayyad period precisely Muawiyah's leadership was the first time a currency printing was carried out. At that time, the printing of the currency still continued the Sasanid model in which some words of monotheism were added as had been done when Khulafa 'Ar-Rashidin. During the leadership of Abdul Malik Ibn Marwan, after successfully conquering Abdullah bin Zubair and Mush'ab bin Zubair, he unified the printing of money and then in $76 \mathrm{H}$ printed the Islamic currency which accentuates its own Islamic pattern, by removing the Byzantine and Persian signs. Thanks to that, Abdul Malik bin Marwan was said to be the first Muslim to issue a dinar and dirham which embraced Islam itself. This paper uses a descriptive-qualitative method based on a socio-historical approach, which will examine the events of the past about the history of Muawiyah money until now. Based on a little about the history of money, it can be concluded that money was originally from gold and silver, then continued to camel skin. Until finally the agreed money is made of paper money. Until the money prevailing in society today is money made from paper money. Then the type of currency used for the State of Indonesia is the name of the Rupiah, then abbreviated as "Rp" for all regions and regions that exist throughout the Republic of Indonesia.
\end{abstract}

Keywords: History, Bani Umayyah, Muawiyah bin Abu Sufyan, Currency.

\section{Pendahuluan}

Uang ialah sesuatu yang begitu vital bagi kelangsungan ekonomi dan mendominasi dalam analisis ekonomi makro. ${ }^{1}$ Uang juga diketahui sebagai suatu yang diakui universal oleh penduduk menjadi media pembayaran yang sah, baik dipakai untuk membeli barang/jasa ataupun

${ }^{1}$ Eko Suprayitno, Ekonomi Islam, Pendekatan Ekonomi Makro Islam Dan Konvensional (Yogyakarta: Graha Ilmu, 2005). 
membayar hutang-piutang. Maksudnya, uang adalah bagian yang vital dalam kehidupan manusia karena sebagai media pelancar lalu lintas barang/jasa untuk seluruh transaksi ekonomi. ${ }^{2}$ Jauh sebelum bangsa Barat mengenal uang, Umat Islam telah mengenal mata uang, baik pada zaman pra kenabian Muhammad, masa Khulafa' Ar-Rasyidin, dan masa dinastidinasti penerusnya, termasuk dinasti Umayyah.

Pasca-pemerintahan Khulafa' Ar-rasyidin lahir sebuah pemerintahan baru Islam yang dikenal dengan Daulah Umayyah, kepemimpinan Daulah Umayyah berasal dari nama Umayyah ibn Abu Syam ibn Abdi Manaf. ${ }^{3}$ Sebuah birokrasi yang diraih dengan berbagai cara "kudeta" dan menuai kontroversi hebat antara Ali dan Muawiyah.4 Berdirinya Bani Umayyah tidak bisa dipisahkan dari sosok Muawiyah Ibn Abi Sofyan. Muawiyah masuk Islam diusia yang masih belia, jauh sebelum keluarga Abu Sofyan lainnya masuk Islam.

Sejarawan menilai negatif terhadap sosok Muawiyah dan perjuangannya. Keberhasilannya mendapatkan pengakuan hukum atas kekuasaan ketika perang Siffin diraih melalui jalan arbitrasi yang culas. Muawiyah dituduh pengkhianat atas konsep demokrasi dalam Islam. Dia awalnya mengganti pimpinan negara dari seseorang yang terpilih oleh rakyat ke sistem monarkhi di mana kekuasaan dipegang langsung oleh raja yang diwariskan turun temurun. Sedangkan kalau ditinjau dari kepribadian dan prestasi politiknya yang mengagumkan sesungguhnya

\footnotetext{
${ }^{2}$ Anita Rahmawaty, "Uang Dan Kebijakan Moneter Dalam Perspektif Ekonomi Islam," EQUILIBRIUM: Jurnal STAIN Kudus 1, no. 2 (2013): 181-199., hlm. 182.

${ }^{3}$ Ahmad Masrul Anwar, "Pertumbuhan Dan Perkembangan Pendidikan Islam Pada Masa Bani Ummayah,” Jurnal Tarbiyah 1, no. 1 (2015): 47-76.

${ }^{4}$ Boedi Abdullah, Peradaban Pemikiran Ekonomi Islam (Bandung: Pustaka Setia, 2010)., hlm. 111.
} 
Muawiyah ialah sosok pribadi yang sempurna serta pimpinan besar dan memiliki bakat. ${ }^{5}$

Sebagai khalifah pertama dari Bani Umayyah, tentu Muawiyah bin Abu Sufyan lebih fokus membangun di bidang keamanan, namun ada beberapa pemikirannya di bidang ekonomi seperti mencetak mata uang. Sebagaimana diketahui pada masa Rasulullah dan Khulafaur Rasyidin, sudah mengenal uang sebagai alat tukar dan pembayaran. Namun, barter juga tidak ditinggalkan kala itu, bahkan menjadi penguat kegiatan ekonomi. Seiring dengan berjalannya waktu, barter dinilai tidak efektif dan efissien lagi karena terlalu memakan waktu yang cukup lama. ${ }^{6}$

Jauh sebelum masyarakat Barat memakai uang dalam bertransaksi, orang Islam sudah mengenal media pertukaran dan pengukur nilai, bahkan al-Qur'an secara tersirat mengatakan bahwa media pengukur nilai yakni emas dan perak dalam beberapa ayat. Beberapa ahli fiqh mentafsirkan emas dan perak sebagai dinar dan dirham. Sebelum ditemukannya uang sebagai media tukar, transaksi dilaksanakan memakai sistem barter, yakni barang ditukar dengan barang dan barang dengan jasa. ${ }^{7}$

Pemikiran Al-Ghazali tentang uang bermula dari pendapat AlGhazali terkait barter, misal unta seharga 200 dinar dan beberapa helai kain sekian dinar. Sebab uang sebagai media pengukur nilai suatu komoditas, secara otomatis uang berfungsi juga sebagai alat pertukaran. Tetapi, uang tidak dipakai untuk uang itu sendiri, uang dicipta guna kelancaran tukar-menukar dan menetapkan nilai wajar dalam transaksi

\footnotetext{
${ }^{5}$ Ali Mufrodi, Islam Di Kawasan Kebudayaan Arab (Jakarta: Logos Wacana Ilmu, 1997)., hlm. 69.

${ }^{6}$ Taufik Rachman, "Bani Umayyah Dilihat Dari Tiga Fase (Fase Terbentuk, Kejayaan Dan Kemunduran),” JUSPI: Jurnal Sejarah Peradaban Islam 2, no. 1 (2018): 86-98.

${ }^{7}$ Rahmat Ilyas, "Konsep Uang Dalam Perspektif Ekonomi Islam," Jurnal Bisnis dan Manajemen Islam 4, no. 1 (2016): 35-57., hlm. 36.
} 
itu. ${ }^{8}$ Lebih lanjut uang tidak memiliki harga, tapi merepresentasikan harga seluruh barang, ekonom klasik menyebutkan bahwa uang tidak memberi manfaat langsung (direct utility function), namun ketika uang dipakai untuk membeli barang, maka dapat bermanfaat. Dalam ekonomi neoklasik dijelaskan bahwa fungsi uang dimulai dengan adanya daya beli, maka uang memberi manfaat tidak langsung (indirect utility function). ${ }^{9}$ Berdasarkan latar belakang tersebut maka tulisan ini mengupas permasalahan yang dikemas dalam rumusan masalah yang akan membahas terkait sejarah dan perkembangan mata uang masa Muawiyah bin Abu Sufyan.

\section{Metode Penelitian}

Tulisan ini memakai analisis deskriptif-kualitatif di mana pendekatan sosio-historis, yang akan mengkaji peristiwa-peristiwa pada masa silam tentang masa kepemimpinan Muawiyah, pengelolaan keuangan publik serta sejarah dan perkembangan mata uang pada saat itu. Menurut Suyono, ${ }^{10}$ penelitian kualitatif merupakan penelitian yang menggunakan metode pengumpulan fakta detail sebanyak mungkin secara mendalam tentang suatu masalah atau gejala untuk mendapatkan makna sebanyak mungkin sifat masalah atau gejala tersebut. Pendekatan sosiologis merupakan salah satu alat ukur untuk memahami agama. Oleh karena itu, penelitian ini menggunakan pendekatan sosiologis agar mampu mengupas sejarah mata uang pada masa Muawiyah secara tajam dan tuntas dengan pisau analisis yang tepat pula.

\footnotetext{
hlm. 176.

${ }^{8}$ Jalaluddin, “Konsep Uang Menurut Al-Ghazali,” Asy-Syari'ah 16, no. 2 (2014): 169-178.,

${ }^{9}$ Adiwarman A. Karim, Sejarah Pemikiran Ekonomi Islam (Jakarta: Rajawali Press, 2003).

${ }^{10}$ Ariyono Suyono, Kamus Antropologi (Jakarta: Akademi Persindo, 1985)., hlm. 307.
} 


\section{Hasil dan Pembahasan}

\section{A. Biografi Muawiyah bin Abu Sufyan (41-60 H/661-679 M)}

Muawiyah bin Abi Sufyan lahir dua atau empat tahun sebelum Muhammad diangkat sebagai nabi dan rasul. ${ }^{11}$ Nama Umayyah itu berasal dari nama Umayyah ibnu Adi Syam ibnu Abdi Manaf, yaitu salah seorang dari pemimpin-pemimpin kabilah Quraisy di zaman jahiliah. Muawiyah memang memiliki cukup unsur-unsur yang diperlukan untuk berkuasa di zaman jahiliah, karena ia berasal dari keluarga bangsawan dan mempunyai cukup kekayaan serta sepuluh orang putra yang terhormat dalam masyarakat. Orang-orang yang memiliki ketiga macam unsur ini di zaman jahiliah berarti telah mempunyai jaminan untuk memperoleh kekuasaan. ${ }^{12}$

Nama lengkap Muawiyah adalah Muawiyah bin Abi Sufyan bin Harb bin Umayyah bin Abdi Syams bin Manaf. Sebagai keturunan Abdi Manaf, Muawiyah mempunyai hubungan keluarga dengan Nabi Muhammad SAW. Muawiyah bin Abi Sufyan lahir di zaman jahiliah. Ia menganut agama Islam pada hari penaklukan kota Makkah pada tahun 629 M, bersama-sama dengan tokoh-tokoh Quraisy lainnya. Dengan demikian teranglah bahwa Bani Umayyah itu adalah orang-orang yang terakhir masuk Agama Islam, dan juga merupakan musuh-musuh yang paling keras terhadap agama ini pada masa-masa sebelum mereka memasukinya. Tetapi setelah masuk Islam, mereka dengan segera dapat memperlihatkan semangat kepahlawanan yang jarang tandingnya, seolahseolah mereka ingin mengimbangi keterlambatan mereka itu dengan berbuat jasa-jasa yang besar terhadap Agama Islam dan agar orang lupa

\footnotetext{
${ }^{11}$ Muhammad Syafii Antonio, Insiklopedia Peradaban Islam Damaskus (Jakarta Selatan: Tazkia Publishing, 2012), 115.

${ }^{12}$ A Syalabi, Sejarah Kebudayaan Islam 2 (Jakarta Pusat: Pustaka Al-husna, 2003), 21.
} 
kepada sikap dan perlawanan mereka terhadap Agama Islam sebelum mereka memasukinya. Mereka benar-benar telah mencatat prestasi yang baik dalam peperangan yang dilancarkan terhadap orang-orang yang murtad dan orang-orang yang mengaku menjadi Nabi, serta orang-orang yang tidak membayar zakat. ${ }^{13}$

Semenjak berkuasa, Muawiyah mulai mengubah koalisi kesukuan Arab menjadi sebuah sentralisasi monarkis. Ia memperkuat barisan militer dan memperluas kekuasaan administratif negara dan merancang alasanalasan moral dan politis yang baru demi kesetiaan terhadap khalifah. Selanjutnya Ia berusaha meningkatkan pendapatan negara dari penghasilan pribadinya, dari lahan pertanian yang diambil alih dari Bizantium dan Sasania dan dari investasi pembukaan tanah baru dan irigasi. Kebijakan politik dan kekuasaan finansial yang ditempuhnya berasal dari nilai-nilai tradisi Arab, seperti; konsiliasi, konsultasi, kedermawanan dan penghormatan terhadap bentuk-bentuk tradisi kesukuan. ${ }^{14}$

Muawiyah sangat terkenal dengan sifat santunnya (hilm). Pemerintahan Muawiyah ditandai dengan upaya sentralisasi kekuasaan negara, bahkan pemerintahannya didasarkan pada jaringan kerja (networks) pribadi dan ikatan kekerabatan. Namun demikian, beberapa dekade masa pemerintahan Muawiyah, tidak terlepas dari berbagai bentuk perselisihan, seperti warga Madinah menentang Quraisy lantaran merampas kedudukan mereka, kalangan Syiah menginginkan jabatan khilafah dan sebagainya, akan tetapi berkat kecakapan pribadinya serta kekuatan militernya, Muawiyah mampu mengatasinya. ${ }^{15}$

\footnotetext{
${ }^{13}$ Ibid., hlm. 22-23.

${ }^{14}$ Muh Jabir, "Dinasti Bani Umayyah Di Suriah (Pembentukan, Kemajuan Dan Kemundurannya)," Jurnal Hunafa 4, no. 3 (2007): 271-280.

${ }^{15}$ Ibid., hlm. 274.
}

64

Tamaddun: Jurnal Sejarah dan Kebudayaan Islam, Volume (8), Issue (1), July 2020 
Sebagai khalifah pertama dari Bani Umayyah, tentu Muawiyah bin Abu Sufyan lebih fokus membangun di bidang keamanan, namun ada beberapa pemikirannya di bidang ekonomi seperti:

a) Mampu membangun sebuah masyarakat Muslim yang tertata rapi sebagai syarat kondusifnya dalam berekonomi.

b) Oleh para sejarahwan, beliau disebut sebagai orang Islam pertama yang membangun kantor catatan negara dan layanan pos (al-barid)

c) Membangun pasukan Damaskus menjadi kekuatan militer Islam yang terorganisir dan disiplin tinggi

d) Mencetak mata uang, membangun birokrasi seperti fungsi pengumpulan pajak dan administrasi politik

e) Mengembangkan jabatan qadi (hakim) sebagai jabatan professional

f) Menerapkan kebijakan pemberian gaji tetap kepada para tentara ${ }^{16}$

\section{B. Sejarah Mata Uang Masa Kepemimpinan Muawiyah bin Abu} Sufyan

Di era kekuasaan Daulah Umayyah, pencetakan uang masih meniru masa sebelumnya yakni menggunakan mata uang dinar dari Byzantin dan dirham dari Sasanid dengan menambahi beberapa lambang keislaman. Pada masa awal dinasti Umayyah, pencetakan mata uang bukanlah menjadi otorita oknum tertentu dalam birokrasi, selain Khalifah, para gubernur serta pemimpin daerah-daerahpun mencetak uang khusus bagi wilayahnya. Abdul Malik bin Marwan adalah khalifah pertama yang membuat dinar emas dalam jumlah yang terbatas, demikian pula

\footnotetext{
${ }^{16}$ Ahmad Al-Usairy, Sejarah Islam Sejak Zaman Nabi Adam Hingga Abad XX, 1st ed. (Jakarta: MA Azhar, 2006)., hlm. 23.
} 
Abdullah bin Zubair membuat dirham sendiri dan membubuhkan namanya. Hal yang sama juga dilakukan oleh saudaranya Mus'ab bin Zubair saat menjabat gubernur di Irak. ${ }^{17}$

Pencetakan mata uang masa Bani Umawiyah sejak Muawiyah bin Abu Sofyan masih melanjutkan pola Sasanid yakni menambah beberapa kata tauhid seperti ketika masa Khulafa' Ar-Rasyidin. Masa kepemimpinan Abdul Malik bin Marwan, pasca menaklukkan Abdullah bin Zubair dan Mush'ab bin Zubair, ia mempersatukan pencetakan uang. Ketika $76 \mathrm{H}$, ia mencetak mata uang Islam yang beruhkan Islam dan menghilangkan logo Byzantium maupun Persia. Sebab begitu, Abdul Malik bin Marwan merupakan Muslim pertama yang membuat dinar/dirham dengan pola Islam sendiri. ${ }^{18}$

Terjadi perbedaan pendapat yang menjelaskan penyebab Abdul Malik menempa dinar/dirham dengan menggunakan pola Islam tersendiri. Beberapa mengutarakan sebab keagamaan, sebab dinar-dinar sebelumnya dibuat memuat lambang trinitas sebagai ukirannya. Pendapat lain juga mengatakan sebab konflik di antara Abdul Malik dan kerajaan Romawi. Bagaimanapun, kontribusi yang diberikan oleh Abdul Malik telah menciptakan stabilitas politik dan ekonomi, memperkecil pemalsuan mata uang. ${ }^{19}$

Pengurangan manipulasi serta pengetatan terus berjalan ketika kepemimpinan Yazid bin Abdul Malik dan Hisyam bin Abdul Malik. Bahkan Hisyam sesekali melihat dirham lalu diketahui ukurannya berkurang 1 butir. Kemudian ia member hukuman kepada si pembuat dengan 1000 cambuk dan mereka berjumlah 100 orang sehingga ia

\footnotetext{
${ }^{17}$ Wahyuddin, "Uang Dan Fungsinya (Sebuah Telaah Historis Dalam Islam)," JSH: Jurnal Sosial Humaniora 2, no. 1 (2009): 40-54., hlm. 47.

${ }^{18}$ Ressi Susanti, "Sejarah Transformasi Uang Dalam Islam," Jurnal Aqlam: Journal of Islam and Plurality 2, no. 1 (2017): 33-42.

${ }^{19}$ Ibid., hlm. 39.
} 
memberi hukuman untuk setiap 1 keping dengan 100.000 kali cambuk. Begitu seterusnya hingga dinar saat Umawiyah dikenal halus, akurat, dan murni. ${ }^{20}$

Ummat Islam pertama kali mencetak mata uang masa pemerintahan Muawiyah bin Abu Sufyan, pendiri Bani Umayyah pada tahun 661 M, hampir 3 dekade pasca meninggalnya Rasulullah SAW. Layaknya pemimpin, Muawiyah menjadikan semua daerah Islam ketika itu berada di bawah kendali pemerintah pusat lalu menyatukan kekuatan guna melawan Byzantium. Tetapi, ia pun bersusah payah agar mampu menetralkan perbedaan agama yang mendominasi koin emas Byzantium. Di Suriah, koin Byzantium masih dipakai walau kekuasaan Byzantium telah runtuh. Demikianlah, orang Suriah mewakili keseimbangan budaya antara Kekaisaran Byzantium dan Kerajaan Arab.

Abdul Malik Ibn Marwan selaku Khalifah Umayyah kelima, ia memuat kata dari Al-qur'an selama 20 tahun sehingga masalah keislaman jadi lebih terarah. Abdul Malik mendirikan Haram al-Sharif (Kubah Batu) di Yerusalem. Ia juga mengeluarkan dekrit yang menegaskan bahwa seluruh bisnis pemerintahan menggunakan bahasa Arab. Oleh karenanya, gambar Abdul Malik terpatri pada koin mengganti gambar Kaisar Byzantium. Untuk pertama kalinya, simbol salib pun dihapuskan serta kalimat Al-qur'an dimunculkan dalam koin.

Koin emas baru yang bertulis Arab tersebut menyebabkan masalah internasional. Pada tahun 692 M, usaha Abdul Malik guna membayar upeti kepada Byzantium menggunakan koin tersebut ditolak Kaisar Justinian II (669-711). Penolakan tersebut melanggar kesepakatan yang menyebabkan perang terjadi. Koin emas tersebut menyinggung Kaisar Justinian II sebab tidak terdapat lagi lambang trinitas, tetapi diganti dua

\footnotetext{
${ }^{20}$ Ibid., hlm. 40 .
} 
kalimat syahadat menggunakan bahasa Arab. Sejak itulah, lambang Islam akhirnya diberlakukan untuk seluruh mata uang.

Langkah selanjutnya guna menciptakan sistem koin baru Arab yang mempunyai standarisasi maka dimunculkanlah gambar khalifah dalam koin emas, perak, dan tembaga. Beberapa tempat mencetak koin yang berlokasi di wilayah perbatasan mengerahkan tentara guna melawan Byzantium. Hal tersebut menyiratkan bahwa koin-koin tersebut dibuat guna kepentingan militer dan untuk pertama kalinya, koin tersebut mencantumkan khalifah. Selain itu, dibalik koin menampilkan obyek yang dikenal sebagai qutb (tongkat) yang dikelilingi kalimat syahadat. Koinkoin tersebut dikeluarkan selama 40 tahun, sejak tahun 693 M sampai 697 M. Pada waktu yang bersamaan, di Mesir dicetaklah koin yang memiliki lebih sedikit variasi. Mesir hanya memakai 1 tempat percetakan yakni di Alexandria. Koin tersebut dibuat dari tembaga kecil dan tebal, tanpa koin emas dan perak.

Pencetakan koin di Arab kebanyakan mirip model yang ada, yakni gambar pemimpin negara di bagian depan, sedang di baliknya figur atau lambang budaya lain. Namun, pada tahun $697 \mathrm{M}$ koin emas hanya menampilkan tulisan Arab yang mayoritas bersumber dari al-Qur'an. Reformasi fundamental tersebut melahirkan mata uang universal yang sepenuhnya Islami, cocok dipakai negara-negara Islam yang mulai menghindari gambar sosok manusia.

\section{Perkembangan Mata Uang}

Dalam sejarah dijelaskan bahwa selain dinar dan dirham murni berlaku juga mata uang lainnya, yakni uang dinar dan dirham tidak murni, "fulus" dan uang kertas. Uang tidak murni awalnya beredar terbatas, lalu mulai beredar luas terlebih pasca Khalifah Al-mutawakkil wafat serta memberlakukan secara resmi. Tetapi, uang dinar dan dirham 
murni masih diakui sebagai mata uang resmi sehingga peredarannya di masyarakat tinggi. Selanjutnya, seiring dengan berkembangnya kegiatan ekonomi serta terbatasnya pasokan emas dan perak murni, pada akhirnya ummat Islam mulai beralih dari keduanya dan berpindah memakai uang tidak murni sampai akhirnya memakai "fulus". ${ }^{21}$

Pembuktian yang menunjuk "fulus" sudah ada serta dipakai di Negara-negara Islam saat awal yakni berupa fatwa beberapa tabi'in terkait "fulus" pada saat mendiskusikan masalah-masalah fiqh. Seperti ulama' Ibrahim An-naqha'i yang memberi fatwa dengan bolehnya bertransaksi akad salam menggunakan "fulus", selain itu, ulama' Mujahid juga memberi fatwa yakni menukar 1 "fulus" dengan 2 "fulus" boleh apabila pelaksanaannya dari tangan ke tangan. Pada saat itu, eksistensi uang "fulus" hanya sebatas uang penunjang yang dipakai bertransaksi untuk jumlah sedikit. Uang emas dan perak yang tetap menjadi uang utama. ${ }^{22}$

Pada masa berikutnya, kegiatan perdagangan banyak dilakukan menggunakan "fulus" sampai akhirnya "fulus" menjadi uang dan peredarannya tinggi. Bahkan saat pemerintahan Mamluk serta abad ke-7 sampai ke-8 H, "fulus" menjadi uang utama (resmi) suatu negara. Namun, terkait uang kertas apakah pernah dikenalkan hingga dipakai oleh Negara Islam (dahulu) jumhur ulama' berbeda pendapat. Beberapa meyakini negara Islam belum pernah menggunakan uang kertas, namun lainnya berpendapat ummat Islam pernah menggunakannya saat beberapa periode. Tanpa mengabaikan perbedaan pendapat itu, sejarah mencatat bahwa pada akhir Dinasti Usmaniyah uang kertas telah beredar dan

${ }^{21}$ Wahyuddin, "Uang Dan Fungsinya (Sebuah Telaah Historis Dalam Islam).", hlm. 48.

${ }^{22}$ Ibid., hlm. 48. 
berlaku. Pada tahun $1254 \mathrm{H}$ Daulah Usmaniyah menerbitkan mata uang kertas yang disebut "al-Qo'imah" yang berlaku selama 23 tahun. ${ }^{23}$

Pada 1839 Daulah Usmaniyah mencetak uang kertas (banknote) bernama "ghaima", tetapi nilai tukarnya terus melemah hingga berdampak atas hilangnya kepercayaan masyarakat. ${ }^{24}$ Saat PD I tahun 1914, Turki sebagaimana negara lain mendeklarasikan uang kertas sebagai mata uang sah lalu membatalkan penggunaan dinar dan dirham sebagai mata uang yang sah. ${ }^{25}$ Saat itu mulailah pemberlakuan uang kertas sebagai satusatunya mata uang untuk semua negara. Termasuk yang berlaku hingga saat ini disebut "fiat money". Hal tersebut karena kemampuan uang dengan fungsinya sebagai media tukar dan mempunyai daya beli tidak didasarkan karena uang tersebut dilatarbelakangi oleh emas. ${ }^{26}$

Zaman dulu, uang didasarkan pada emas sebab mengikuti standar emas. Tetapi, kondisi tersebut ditinggalkan dalam sebagian ekonomi dunia tahun 1931, lalu pada 1976 perekonomian dunia seluruhnya meninggalkannya. Hingga saat ini, uang kertas telah menjadi media tukar yang telah disahkan pemerintah dan uang kertas menjadi standar media tukar. Khalifah Umar bin Khattab mengatakan mata uang bisa diciptakan dari bahan apapun hingga kulit unta sekalipun. Ketika sebuah benda telah disepakati menjadi mata uang sah, barang itu otomatis beralih fungsi dari barang biasa menjadi media tukar yang sah dengan berbagai fungsi dan turunannya. ${ }^{27}$

${ }^{23}$ Ibid., hlm. 49.

${ }^{24}$ Sri Ramadhan, "Implementasi Uang Beredar (M2) Sebagai Public Goods and Flow Concept Dan Uang Sebagai Private Goods and Stock Concept," JEBI: Jurnal Ekonomi dan Bisnis Islam 2, no. 2 (2017): 145-157.

\footnotetext{
${ }^{25}$ Mustafa Edwin Nasution, Pengenalan Eksklusif Ekonomi Islam (Jakarta: KENCANA, 2006).

${ }^{26}$ Rozalinda, Ekonomi Islam: Teori Dan Aplikasiny Pada Aktivitas Ekonomi (Jakarta: Rajawali Pers, 2014)., hlm. 2.

${ }^{27}$ Nurul Huda and Dkk, Ekonomi Makro Islam: Pendekatan Teoritis (Jakarta: KENCANA, 2009)., hlm. 92.
} 
Ketika uang kertas menjadi media pembayaran yang sah, meskipun tidak didasarkan pada emas, maka status hukumnya sama dengan dinar dan dirham di mana sejak al-Qur'an turun telah menjadi media pembayaran yang sah. Uang kertas pun diakui sebagai harta kekayaan sehingga wajib ditunaikan zakatnya. Zakatpun sah jika ditunaikan berbentuk uang kertas. Uang kertas bisa pula digunakan sebagai media pembayaran mahar. Terdapat kelebihan menggunakan uang kertas untuk kegiatan ekonomi modern, salah satunya mudah dibawa-bawa, biaya produksi lebih sedikit dibanding uang logam, dan bisa dipecah menjadi jumlah berapapun. Namun, penggunaan uang kertas juga memiliki kelemahan misalnya, tidak ada jaminan kestabilan nilai tukar layaknya uang emas dan perak yang memiliki stabilitas nilai tukar. Selain itu, apabila uang kertas dicetak dalam jumlah berlebih, maka akan menyebabkan terjadinya inflasi, nilai uang mengalami penurunan, serta harga barang mengalami kenaikan. ${ }^{28}$

Pada dasarnya, nilai uang dapat dilihat dari 2 sisi, yakni nilai uang ditinjau dari pembuatan dan penggunaannya. ${ }^{29}$ Jika ditinjau dari bahan pembuatnya, terdapat 2 jenis: (1) Nilai intrinsik; nilai uang berdasar bahan-bahan pembuatannya. Contoh, untuk mencetak uang logam Rp200 dibutuhkan logam perak seberat 2 gram. Maka, uang sebesar Rp200 seharga dengan perak senilai 1 gram. Hal tersebut disebut nilai intrinsik uang. (2) Nilai nominal; yakni nilai yang ada di setiap mata uang itu sendiri. Uang pecahan Rp50.000 tercantum angka lima puluh ribu rupiah, maka nilai nominal uang itu yakni lima puluh ribu rupiah. ${ }^{30}$

\footnotetext{
${ }^{28}$ Susanti, "Sejarah Transformasi Uang Dalam Islam." hlm. 41.

${ }^{29}$ Mishkin F S, The Economic of Money, Banking, and Financial Markets, Fourth. (New Jersey: Pearson Education Inc, 2008).

${ }^{30}$ Jamaluddin, "Fiat Money: Masalah Dan Solusi," Jurnal Akuntansi Multiparadigma 4, no. 1 (2013): 257-268.
} 
Dari kedua nilai uang tersebut memunculkan 2 istilah, yakni "fiducier money" dan "full bodied money". "Fiducier money" adalah uang mempunyai nilai nominal lebih besar daripada nilai intrinsiknya. Contoh, semua uang kertas. Sedangkan "full bodied money" adalah uang mempunyai nilai nominal sama dengan nilai intrinsiknya. Contoh, semua jenis mata uang koin sehingga uang koin disebut juga "full bodied money". Sebagai media tukar ataupun media ukur maka nilai yang diterima dan yang diserahkan adalah sama tanpa memperhatikan alat tukar. ${ }^{31}$

Dari uraian di atas, maka dapat disimpulkan bahwa alat tukar yang ideal adalah alat tukar yang mempunyai instrinsik dan nilai nominal yang sama atau "full bodied money" seperti yang diisyaratkan al-Qur'an dan berbagai hadits Rasul. Jika dilihat dari penggunaannya, nilai uang ada 2 jenis: 1) Nilai internal; kemampuan sebuah mata uang jika ditukar dengan barang. Disebut juga, nilai internal uang yaitu daya beli uang terhadap barang/jasa. Contohnya, uang senilai Rp500.000 bisa ditukar dengan emas sebarat 1 gram. Artinya, nilai internal uang Rp500.000 sebesar emas 1 gram; 2) Nilai eksternal; kemampuan mata uang dalam negeri jika dibanding dengan mata uang asing (valuta asing). Disebut juga, nilai eksternal uang yaitu daya beli uang dalam negeri terhadap mata uang asing/kurs. Contoh, uang Rp500.000 mampu ditukar dengan 50 dollar AS (US\$ $50=$ Rp500.000). Artinya, uang Rp 500.000 memiliki nilai eksternal sama dengan 50 dollar AS. ${ }^{32}$

Perbedaan nilai mata uang antar Negara menyebabkan keuntungan dan kerugian terhadap masing-masing negara tergantung transaksi ekonominya. Jika suatu Negara melakukan devaluasi terhadap mata uangnya, maka Negara tersebut menurunkan kemampuannya untuk

\footnotetext{
${ }^{31} \mathrm{Ibid} .$, hlm. 259.

${ }^{32}$ Ibid., hlm. 260.
} 
membeli barang-barang dari luar negeri atau dengan kata lain kemampuan nilai uangnya semakin menurun dan memperkuat nilai mata uang asing terhadap mata uangnya yang berakibat daya beli mata asing semakin meningkat. Implikasi dari kejadian di atas menyebabkan Negara yang terdevaluasi mata uangnya harus membayar lebih mahal terhadap produk dan jasa dari luar negeri, sedangkan orang luar negeri akan membayar lebih murah produk dan jasa dari negara yang terdevaluasi mata uangnya. ${ }^{33}$

\section{Kesimpulan}

Pencetakan mata uang masa Bani Umawiyah sejak Muawiyah bin Abu Sofyan masih melanjutkan pola Sasanid yakni menambah beberapa kata tauhid seperti ketika masa Khulafa' Ar-Rasyidin. Periode kepemimpinan Abdul Malik bin Marwan, pasca menaklukkan Abdullah bin Zubair dan Mush'ab bin Zubair, ia mempersatukan tempat mencetak uang. Pada $76 \mathrm{H}$, ia mencetak mata uang Islam yang beruhkan Islam tersendiri, dengan menghapuskan tanda Byzantium maupun Persia. Oleh karena itu, Abdul Malik bin Marwan merupakan Muslim pertama yang menerbitkan dinar/dirham dengan pola Islam sendiri.

Berdasarkan sekelumit tentang sejarah uang, maka dapat ditarik kesimpulan bahwa uang pada mulanya dari emas dan perak, kemudian berlanjut kepada kulit unta. Hingga pada akhirnya uang yang disepakati terbuat dari uang kertas. Hingga uang yang beredar ditangan masyarakat saat ini ialah uang yang terbuat dari uang kertas. Kemudian jenis mata uang yang dipakai untuk Negara Indonesia ialah dengan nama mata uang rupiah kemudian disingkat dengan " $R \mathrm{p}$ " untuk seluruh daerah dan wilayah yang ada di seluruh NKRI.

\footnotetext{
${ }^{33}$ Ibid., hlm. 261.
} 


\section{Daftar Pustaka}

Abdullah, Boedi. Peradaban Pemikiran Ekonomi Islam. Bandung: Pustaka Setia, 2010.

Al-Usairy, Ahmad. Sejarah Islam Sejak Zaman Nabi Adam Hingga Abad XX. 1st ed. Jakarta: MA Azhar, 2006.

Anwar, Ahmad Masrul. "Pertumbuhan Dan Perkembangan Pendidikan Islam Pada Masa Bani Ummayah." Jurnal Tarbiyah 1, no. 1 (2015): 4776.

Huda, Nurul, and Dkk. Ekonomi Makro Islam: Pendekatan Teoritis. Jakarta: KENCANA, 2009.

Ilyas, Rahmat. "Konsep Uang Dalam Perspektif Ekonomi Islam." Jurnal Bisnis dan Manajemen Islam 4, no. 1 (2016): 35-57.

Jabir, Muh. “Dinasti Bani Umayyah Di Suriah (Pembentukan, Kemajuan Dan Kemundurannya)." Jurnal Hunafa 4, no. 3 (2007): 271-280.

Jalaluddin. “Konsep Uang Menurut Al-Ghazali." Asy-Syari'ah 16, no. 2 (2014): 169-178.

Jamaluddin. "Fiat Money: Masalah Dan Solusi." Jurnal Akuntansi Multiparadigma 4, no. 1 (2013): 257-268.

Karim, Adiwarman A. Sejarah Pemikiran Ekonomi Islam. Jakarta: Rajawali Press, 2003.

Mufrodi, Ali. Islam Di Kawasan Kebudayaan Arab. Jakarta: Logos Wacana Ilmu, 1997.

Nasution, Mustafa Edwin. Pengenalan Eksklusif Ekonomi Islam. Jakarta: 
KENCANA, 2006.

Rachman, Taufik. “Bani Umayyah Dilihat Dari Tiga Fase (Fase Terbentuk, Kejayaan Dan Kemunduran)." JUSPI: Jurnal Sejarah Peradaban Islam 2, no. 1 (2018): 86-98.

Rahmawaty, Anita. “Uang Dan Kebijakan Moneter Dalam Perspektif Ekonomi Islam." EQUILIBRIUM: Jurnal STAIN Kudus 1, no. 2 (2013): 181-199.

Ramadhan, Sri. “Implementasi Uang Beredar (M2) Sebagai Public Goods and Flow Concept Dan Uang Sebagai Private Goods and Stock Concept." JEBI: Jurnal Ekonomi dan Bisnis Islam 2, no. 2 (2017): 145-157.

Rozalinda. Ekonomi Islam: Teori Dan Aplikasiny Pada Aktivitas Ekonomi. Jakarta: Rajawali Pers, 2014.

S, Mishkin F. The Economic of Money, Banking, and Financial Markets. Fourth. New Jersey: Pearson Education Inc, 2008.

Suprayitno, Eko. Ekonomi Islam, Pendekatan Ekonomi Makro Islam Dan Konvensional. Yogyakarta: Graha Ilmu, 2005.

Susanti, Ressi. "Sejarah Transformasi Uang Dalam Islam." Jurnal Aqlam: Journal of Islam and Plurality 2, no. 1 (2017): 33-42.

Suyono, Ariyono. Kamus Antropologi. Jakarta: Akademi Persindo, 1985.

Wahyuddin. "Uang Dan Fungsinya (Sebuah Telaah Historis Dalam Islam)." JSH: Jurnal Sosial Humaniora 2, no. 1 (2009): 40-54. 
Tamaddun: Jurnal Sejarah dan Kebudayaan Islam, Volume (8), Issue (1), July 2020 